\title{
Comparison of fine needle aspiration cytology and core needle biopsy findings with excisional biopsy in breast malignancy
}

\author{
Uma Bhatta ${ }^{1,3}$, Shovana Karki ${ }^{1}$, Gita Sayami ${ }^{1}$, Dosti Regmi ${ }^{2}$ \\ ${ }^{1}$ Department of Pathology, Tribhuvan University Teaching Hospital, Kathmandu, Nepal \\ ${ }^{2}$ Department of Radiology, Kanti Children's Hospital, Kathmandu, Nepal \\ ${ }^{3}$ Department of Pathology, Kanti Children's Hospital, Kathmandu, Nepal
}

\author{
Keywords: \\ Biopsy; \\ Breast; \\ Cytology; \\ Estrogen receptor; \\ HER-2/neu; \\ Large-Core Needle;
}

\begin{abstract}
Background: Fine needle aspiration cytology and core needle biopsy are reliable procedures for breast cancer detection. Core needle biopsy is an established alternative to surgical biopsy for diagnosis and prognostication. However, there may be a concern that core needle biopsy may be less reliable than excisional biopsy. The aim of this study was to compare the cytological/core needle biopsy finding with excisional histopathological diagnosis and determine their hormonal status.
\end{abstract}

Materials and Methods: A prospective study of 65 patients was conducted after obtaining a detailed clinical data. The comparison of the fine needle aspiration cytology/core needle biopsy finding with excisional histopathological diagnosis of breast malignancy was carried out after data analysis. Their ER, PR and HER-2/neu status was also studied in available cases.

Results: Out of the 65 cases of breast malignancy, $69.2 \%$ of cases had undergone fine needle aspiration, $60 \%$ cases core needle biopsy and $93.8 \%$ cases excisional biopsy. The most common carcinoma was invasive carcinoma of no special type. The diagnostic accuracy of fine needle aspiration and core needle biopsy was almost equal, however, core needle biopsy could assess the histological typing and biomarker status. The hormonal status was assessed in $69.23 \%$ cases, among them $35.6 \%$ cases were triple negative carcinomas.

Conclusions: Core needle biopsy was superior to fine needle aspiration cytology in the diagnosis of breast lesions in terms of diagnostic accuracy. Thus, our result provides valuable prognostic information to guide the decision-making process for the treatment of a patient with invasive carcinoma.

\section{Correspondence:}

Dr. Uma Bhatta, MBBS, MD

Consultant Pathologist

Department of Pathology, Kanti Children's Hospital, Kathmandu, Nepal ORCID ID: 0000-0002-7033-858X

Email:umabhatta27@gmail.com

Received : July $27^{\text {th }} 2019$; Accepted : September $16^{\text {th }} 2019$

Citation: Bhatta U, Karki S, Sayami G, Regmi D. Comparison of fine needle aspiration cytology or core needle biopsy findings with excisional biopsy in breast malignancy. J Pathol Nep 2019;9:156470. DOI: $10.3126 /$ jpn.v9i2.25031

Copyright: This is an open-access article distributed under the terms of the Creative Commons Attribution 4.0 International License, which permits unrestricted use, distribution, and reproduction in any medium, provided the original author and source are credited.

\section{INTRODUCTION}

Breast cancer is a heterogeneous disease at the clinical, morphological and molecular levels with varied responses to therapy. Pre-operative pathology diagnosis constitutes an essential part of the work-up of breast lesions. The role of Fine needle aspiration (FNA) is a less traumatic alternative to core needle biopsy (CNB) and the main goal is to confirm benign clinical and radiological findings in order to avoid unnecessary surgery. ${ }^{1-2}$ Advantage of CNB is the ability to diagnose invasiveness and thus allow the patient to undergo a single operation including sentinel node biopsy in cases diagnosed as invasive. Hormone receptor status and surface 
epithelial growth-factor receptors are the main predictive factor. ${ }^{3}$ This study thus helps us to categorize different histological types of breast malignancy and to determine their ER, PR and HER-2/neu status which carries both the prognostic and predictive significance.

\section{MATERIALS AND METHODS}

A prospective study was carried out after ethical clearance from the institutional review board. The study was carried out form 14th April 2017 to 13th April 2018 among patients visiting Tribhuvan University Teaching Hospital, Maharajgunj and was suspected of having breast carcinoma based upon clinical and radiological examination. After obtaining a detailed clinical data, the patient was subjected to FNAC or core needle biopsy. The consent of the patient was taken before the procedure. The data collection was done in predesigned proforma and data entry was done in SPSS and results were computed using Statistical Package for Social Sciences (SPSS) version 20. Frequency calculation and cross tabulation were done for data analysis.

\section{RESULTS}

During the study period, a total of 472 patients underwent FNAC for breast lump. Among them 190 cases had breast mass excised. Among all 472 patients with a breast lump, 65 cases were clinically/radiologically suspected for breast carcinoma. The age of the patients with suspicion of breast carcinoma ranged from 26 years to 82 years with a mean age of $47.38 \pm 11.9$ years. The most common age group was $40-49$ years. Most of the patients were female $(\mathrm{n}=63 ; 96.9 \%)$ with $2(3.1 \%)$ male patients. Almost half of the total 65 suspected cases of breast cancer $(50.8 \%)$ were on oral contraceptive pills, $2 / 3(65.1 \%)$ cases were multiparous, $15.9 \%$ women had given birth to a single child and $19 \%$ women were nulliparous. The most common age of menarche was 13 years $(23.8 \%)$ and 14 years $(23.8 \%)$. Among the study population, $28(42.9 \%)$ cases were postmenopausal women. The average age of menopause was $47.85 \pm 2.4$ years. Among all the suspected patients, $4(6.2 \%)$ patients had a positive family history for breast cancer.

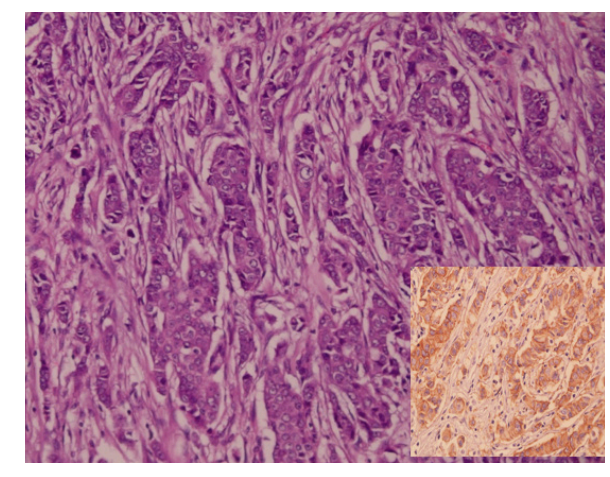

Figure 1: Histological section of Invasive carcinoma of no special type, Grade III showing moderately pleomorphic tumor cells arranged in solid sheets (HE stain, X200). These cells are HER-2/neu positive (inset, IHC, X400).
Of all 65 patients, the right breast was slightly more involved by carcinoma (50.8\%) than the left one (47.7\%). Bilateral breasts were involved in $1.5 \%$ of cases. Forty two (64.6\%) patients presented with breast mass in the upper outer quadrant followed by retroareolar area (12.3\%).

Out of the 65 suspected cases of breast malignancy, 45 (69.2\%) cases had undergone FNAC, 39 (60\%) cases core needle biopsy and $61(93.8 \%)$ cases excisional biopsy. All three procedures were performed in $15(23 \%)$ cases. The FNAC of breast lump reported 31 cases $(68.9 \%)$ of ductal carcinoma, suspicious for malignancy in five cases $(11.1 \%)$, proliferative breast disease with atypia three cases $(6.7 \%)$, one phyllodes tumor $(2.2 \%)$, one carcinoma with apocrine differentiation $(2.2 \%)$ and four cases $(8.9 \%)$ inadequate for opinion.

In $\mathrm{CNB}$, invasive carcinoma of no special type (fig. 1) constituted of $74.4 \%$, Invasive lobular carcinoma, and malignant phyllodes tumor $7.7 \%$ each and Invasive micropapillary carcinoma (fig.2) 2.6\%. 7.7\% of cases were inadequate for diagnosis.

The most common diagnosis in FNAC was ductal carcinoma and in excisional biopsy 23 cases turned out to be Invasive carcinoma of no special type, one case Multifocal invasive carcinoma, one case Carcinoma with medullary features and two cases Metaplastic carcinoma (Table 1). The sensitivity and specificity of FNAC were high with a sensitivity of $91.89 \%$ (CI- $78.09 \%-98.30 \%$ ) and specificity of $100 \%$ (CI- 39.76\%- 100.00\%).

19 cases had undergone both the FNA and CNB. Among them, 13 cases were ductal carcinoma in FNAC and in CNB 12 cases turned out to be Invasive carcinoma of no special type, one case was inadequate. FNA and CNB findings showed good concordance (Table 2).

Comparison of CNB with excisional biopsy findings revealed that out of $35 \mathrm{CNB}$ cases, 25 cases of Invasive carcinoma of no special type in CNB, 24 (96\%) cases correlate well with excisional biopsy findings. One case

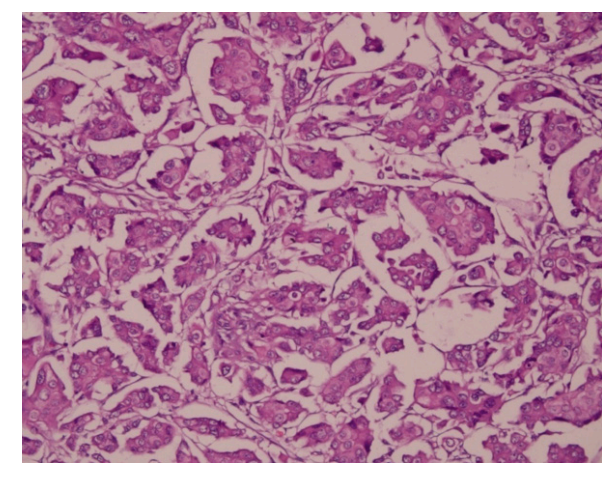

Figure 2: Histological section of Invasive micropapillary carcinoma (HE stain, X200). 
Table 1: Comparison between FNA and Excisional biopsy findings

\begin{tabular}{|c|c|c|c|c|c|c|c|c|c|}
\hline \multicolumn{10}{|c|}{ Excisional biopsy findings } \\
\hline FNA Diagnosis & $\begin{array}{l}\text { Invasive ca of } \\
\text { no special type }\end{array}$ & $\begin{array}{l}\text { Invasive } \\
\text { lobular ca }\end{array}$ & Metaplastic ca & $\begin{array}{c}\text { Ca with } \\
\text { apocrine } \\
\text { differentiation }\end{array}$ & $\begin{array}{l}\text { Ca with } \\
\text { medullary } \\
\text { feature }\end{array}$ & $\begin{array}{l}\text { Malignant } \\
\text { phyllodes } \\
\text { tumor }\end{array}$ & $\begin{array}{c}\text { Multifocal } \\
\text { invasive Ca } \\
\text { (Mucinous Ca } \\
\text { and Ca of no } \\
\text { special type) }\end{array}$ & $\begin{array}{l}\text { Microinvasive } \\
\text { ca with } \\
\text { extensive DCIS }\end{array}$ & Total \\
\hline Ductal ca* & 23 & 0 & 2 & 0 & 1 & 0 & 1 & 0 & 27 \\
\hline $\begin{array}{l}\text { Phyllodes } \\
\text { tumor }\end{array}$ & 0 & 0 & 0 & 0 & 0 & 1 & 0 & 0 & 1 \\
\hline $\begin{array}{l}\text { Carcinoma } \\
\text { with apocrine } \\
\text { differentiation }\end{array}$ & 0 & 0 & 0 & 1 & 0 & 0 & 0 & 0 & 1 \\
\hline $\begin{array}{l}\text { Suspicious for } \\
\text { malignancy }\end{array}$ & 5 & $\mathbf{0}$ & $\mathbf{0}$ & $\mathbf{0}$ & $\mathbf{0}$ & $\mathbf{0}$ & 0 & $\mathbf{0}$ & 5 \\
\hline $\begin{array}{l}\text { Proliferative } \\
\text { breast disease } \\
\text { with atypia }\end{array}$ & 2 & 0 & 0 & 0 & 0 & 0 & 0 & 1 & 3 \\
\hline Inadequate & 2 & 2 & 0 & 0 & 0 & 0 & 0 & 0 & 4 \\
\hline Total & 32 & 2 & 2 & 1 & 1 & 1 & 1 & 1 & 41 \\
\hline
\end{tabular}

*Ca- Carcinoma

Table 2: Comparison between FNA and CNB among study population

\begin{tabular}{lcccc}
\hline FNA Diagnosis & $\begin{array}{c}\text { Excisional biopsy findings } \\
\text { Invasive carcinoma of } \\
\text { no special type }\end{array}$ & $\begin{array}{c}\text { Invasive lobular } \\
\text { carcinoma }\end{array}$ & Inadequate & Total \\
\hline Ductal carcinoma & 12 & 0 & 1 & 13 \\
\hline Suspicious for malignancy & 1 & 0 & 1 & 2 \\
Inadequate & 1 & 2 & 0 & 3 \\
Proliferative breast disease with atypia & 1 & 0 & 0 & 1 \\
\hline Total & $\mathbf{1 5}$ & $\mathbf{2}$ & $\mathbf{2}$ & $\mathbf{1 9}$ \\
\hline
\end{tabular}

Table 3: Comparison between CNB and Excisional biopsy findings

\begin{tabular}{|c|c|c|c|c|c|c|c|}
\hline \multirow[b]{2}{*}{ Core Needle Biopsy Findings } & \multicolumn{4}{|c|}{ Excisional biopsy findings } & \multirow[b]{2}{*}{$\begin{array}{c}\text { Malignant } \\
\text { phyllodes tumor }\end{array}$} & \multirow[b]{2}{*}{ Fibrosarcoma } & \multirow[b]{2}{*}{ Total } \\
\hline & $\begin{array}{l}\text { Invasive ca. of no } \\
\text { special type }\end{array}$ & $\begin{array}{c}\text { Carcinoma } \\
\text { with medullary } \\
\text { features }\end{array}$ & $\begin{array}{c}\text { Invasive } \\
\text { micropapillary } \\
\text { carcinoma }\end{array}$ & $\begin{array}{l}\text { Invasive lobular } \\
\text { carcinoma }\end{array}$ & & & \\
\hline $\begin{array}{l}\text { Invasive carcinoma of no } \\
\text { special type }\end{array}$ & 24 & 1 & 0 & 0 & 0 & 0 & 25 \\
\hline $\begin{array}{l}\text { Invasive micropapillary } \\
\text { carcinoma }\end{array}$ & 0 & 0 & 1 & 0 & 0 & 0 & 1 \\
\hline Invasive lobular carcinoma & 0 & 0 & 0 & 3 & 0 & 0 & 3 \\
\hline Inadequate & 3 & 0 & 0 & 0 & 0 & 0 & 3 \\
\hline Malignant phyllodes tumor & 0 & 0 & 0 & 0 & 2 & 1 & 3 \\
\hline Total & 27 & 1 & 1 & 3 & 2 & 1 & 35 \\
\hline
\end{tabular}

Table 4: Various histopathological subtype of breast carcinoma in excisional biopsy

\begin{tabular}{|c|c|c|}
\hline Histopathological diagnosis & Frequency & Percent \\
\hline Invasive carcinoma of no special type & 46 & $75.4 \%$ \\
\hline Invasive lobular carcinoma & 3 & $4.9 \%$ \\
\hline Malignant phyllodes tumor & 3 & $4.9 \%$ \\
\hline Carcinoma with medullary features & 2 & $3.3 \%$ \\
\hline Metaplastic carcinoma & 2 & $3.3 \%$ \\
\hline Carcinoma with apocrine differentiation & 1 & $1.6 \%$ \\
\hline Invasive micropapillary carcinoma & 1 & $1.6 \%$ \\
\hline Fibrosarcoma & 1 & $1.6 \%$ \\
\hline $\begin{array}{l}\text { Multifocal invasive carcinoma (Mucinous carcinoma grade II and Invasive carcinoma of no } \\
\text { special type grade II) }\end{array}$ & 1 & $1.6 \%$ \\
\hline Microinvasive carcinoma with extensive DCIS & 1 & $1.6 \%$ \\
\hline Total & 61 & $100 \%$ \\
\hline
\end{tabular}




\begin{tabular}{lc}
$\begin{array}{l}\text { Table 5: IHC / hormone receptor status of breast carci- } \\
\text { noma }\end{array}$ & Frequency (\%) \\
\hline \multicolumn{1}{c}{ Hormone receptor status } & $16(35.6)$ \\
\hline $\begin{array}{l}\text { Triple Negative } \\
\text { ER Positive, PR Positive, HER-2/neu } \\
\text { Negative }\end{array}$ & $12(26.7)$ \\
\hline $\begin{array}{l}\text { ER Negative, PR Negative, HER-2/ } \\
\text { neu Positive }\end{array}$ & $5(11.1)$ \\
\hline $\begin{array}{l}\text { ER Positive, PR Negative, HER-2/neu } \\
\text { Negative }\end{array}$ & $4(8.9)$ \\
$\begin{array}{l}\text { ER Negative, PR Positive, HER-2/neu } \\
\text { Negative }\end{array}$ & $4(8.9)$ \\
\hline $\begin{array}{l}\text { ER Positive, PR Positive, HER-2/new } \\
\text { Equivocal }\end{array}$ & $2(4.4)$ \\
\hline $\begin{array}{l}\text { ER Negative, PR Negative, Her-2/neu } \\
\text { Equivocal }\end{array}$ & $1(2.2)$ \\
\hline Triple Positive & $1(2.2)$ \\
\hline Total & $\mathbf{4 5 ( 1 0 0 . 0 )}$ \\
\hline
\end{tabular}

(4\%) turned out to be Carcinoma with medullary features. $4.65 \%$ (3/65) cases were inadequate by CNB (Table 3$)$.

Histopathology showed that invasive carcinoma of no special type (fig. 1) was the commonest variant followed by invasive lobular carcinoma and malignant phyllodes tumor (Table 4). In the present study, most common carcinomas were of grade $2(44.3 \%, \mathrm{n}=61)$ followed by grade $1(31.1 \%$, $\mathrm{n}=61)$ and grade $3(24.6 \%, \mathrm{n}=61)$.

Hormonal status were assessed in 45 cases, triple negative was the commonest type followed by ER Positive, PR Positive, HER-2/neu Negative (Table 5). The frequencies of ER/PR and HER-2/neu status were assessed according to tumor grade (I, II and III). Triple negative cases were more common in Grade III Invasive carcinoma of no special type compared to grade II and grade I. ER+/PR+ and HER-2/neu negative status were most common in grade I and grade II carcinoma.

\section{DISCUSSION}

Breast lesions can usually be detected using various imaging modalities, they are not always typical in appearance and might need cytological or histopathological examination for definitive diagnosis. ${ }^{4}$ Immunohistochemical markers are often used to guide treatment decisions, to classify breast cancer into subtypes that are biologically distinct and behave differently and thus carries prognostic and predictive value. ${ }^{5}$ This study reflects the comparability between FNAC and $\mathrm{CNB}$ in the diagnosis of breast carcinoma considering the histological diagnosis from the excision specimen being the gold standard.

Carcinoma was most commonly diagnosed in the age group of 40-49 years in female patients $(40 \%)$ followed by in the group of 30-39 and 50-59 years (21.5\% each). In a study by Thapa et al. out of the 944 female breast cancer patients,
$263(27.9 \%)$ were $<40$ years $^{6}$. The mean age was $34.6 \pm$ 5.0 years among younger patients compared to $54.1 \pm 9.9$ for those $\geq 40$ years. ${ }^{6}$ As per data from seven major cancer hospitals in Nepal the highest incidence rate of breast cancer was in the age of 45-49 followed by the 55-59 years group. ${ }^{7}$ As per larger studies on sex-incidence of breast carcinoma, it is an uncommon neoplastic condition in men, accounting for not more than $1 \%$ of all breast carcinomas. ${ }^{8}$ We found $3.1 \%$ of the study population was male. This discrepancy was most probably due to the selection of a lesser number of patients in the study.

The relationship between oral contraceptives pills (OCPs) and breast cancer is controversial. In the year 1996, a study that reviewed the use of OCPs resulted only in a small increase in risk (relative risk=1.24) for breast cancer. ${ }^{9}$ There was no significant difference in the development of breast cancer during 10 years after the discontinuation of oral contraceptive use. Ban and Godellas conducted a recent study where they reported that women taking oral contraceptives had a $24 \%$ higher risk of developing cancer compared to those who never took them in their lives and that this risk especially materialized during the use of oral contraceptives. ${ }^{10}$ Changes in the formulation of oral contraceptives overtime, the duration of their use and different oral contraceptive formulation may result in a differentiation of breast cancer risk. In the present study, $50.8 \%$ of cases with breast cancer were using OCPs. The risk of breast cancer declines with the number of children born. Women who have given birth to five or more children have half the breast cancer risk of women who have not given birth. Some evidence indicates that the reduced risk associated with a higher number of births may be limited to hormone receptor-positive breast cancer. ${ }^{11}$ In our study, $65.1 \%$ cases of women with breast cancer were multiparous, $15.9 \%$ of women had given birth to a single child and $19 \%$ of women were nulliparous. This corresponds to the study performed by Balekouzou et al. ${ }^{12}$ 90.8\% women were married and $9.2 \%$ of women with breast carcinomas were unmarried in the current study. Early age of first menarche and late age of menopause increase the risk of developing breast and endometrial carcinoma. Women with menopause at the age of 55 years have 2 times higher risk for developing breast cancer as compared to those with a menopause age of 45.9 In this study, the average age at menarche of cases diagnosed with breast cancer was found to be $14 \pm 1.6$ and the average age of menopause was $47.85 \pm 2.4$. In a study done by Thapa et al., the mean age at menarche was also significantly lower $(13.5 \pm 1.5){ }^{6}$ In a study done by Ozsoy et al., the average age at menarche of cases diagnosed with breast cancer was $14 \pm 1.5$, the average at menopause $48.5 \pm 5.4^{9}$ which was more similar to our study.

Approximately $3-10 \%$ of breast cancer cases are hereditary cancers. It is stated that approximately $85 \%$ of them are associated with BRCA1 and BRCA2 mutations. ${ }^{9}$ These mutations were not assessed in the current study. In a study 
done by B. Thapa et al. family history of breast cancer was evident in $3.0 \%$ of the young women versus $0.3 \%$ in the older one. ${ }^{9}$ In the present study, $6.2 \%$ of all the cases with breast cancer had a positive family history. Of all 65 patients in our study, the right breast was slightly more involved by carcinoma $(50.8 \%)$ than left one $(47.7 \%)$ followed by bilateral (1.5\%). Aljarrah et al. stated that breast cancer occurs almost equally in the right and left breast and most commonly affected the upper outer quadrant (UOQ). ${ }^{13}$ Among all 65 patients in this study, 42 patients i.e. $64.6 \%$ presented with breast mass in upper outer quadrant of the breast followed by retroareolar area $(12.3 \%)$. Deen et al. in their study had found that $46.12 \%$ of patients in whom upper outer quadrant was involved in breast cancer. ${ }^{14}$ The larger mass of breast tissue in the upper outer quadrant is responsible for the commonest occurrence at this location. Early breast cancers situated in central/internal quadrants have a worse prognosis compared with those in lateral quadrants, that is why tumor location is an important part in prognosis in terms of distant metastases and survival. ${ }^{13}$

In the present study $69.2 \%(\mathrm{n}=45)$ cases had undergone FNAC, $60 \%(n=39)$ cases core needle biopsy and $93.8 \%$ $(n=61)$ cases excisional biopsy. All three procedures were performed in $23 \%(n=15)$ cases. Most of the cases had undergone modified radical mastectomy ( $82 \%$ cases) followed by breast conserving surgery ( $16.4 \%$ cases). In a study by Thapa et al., the proportion of breast conserving surgery was higher in young patients $(25.1 \%$ vs. $8.7 \%)$ compared to modified radical mastectomy. ${ }^{6}$ However, in our study, most of the breast conserving surgery was performed in an elderly female. This reason may be due to the increased risk of morbidity in radical surgery in elderly patients.

A comparison of FNAC with excisional biopsy findings in this study revealed that FNAC had 91\% sample adequacy in diagnosing breast carcinoma. Out of 41 FNA cases, 27 cases were ductal carcinoma and in histopathological diagnosis 23 cases turned out to be Invasive carcinoma of no special type and the rest were carcinomas showing other special features. One case of phyllodes tumor reported in FNAC was diagnosed as malignant phyllodes tumor in the final histopathology. Five cases of suspicious for malignancy turned out to be Invasive carcinoma of no special type in histopathology. Three cases of proliferative breast disease with atypia in FNA were diagnosed as Invasive carcinoma of no special type (two cases) and Microinvasive carcinoma with extensive DCIS component (one case) in histopathology. Among four cases inadequate in FNA two cases turned out to the Invasive carcinoma of no special type and two cases in Invasive lobular carcinoma in histopathology (Table 1). The inadequacy may be due to fibrotic mass and ill defined lesion. In a study by Uddin Rupom et al., the overall diagnostic accuracy of FNAC was $100 \% .{ }^{15}$ This may be due to smaller sample size and repeated FNA procedure in inadequate cases. On comparing categorization (C-category) done through FNAC with histopathological findings in the study performed by $\mathrm{M}$. Shaila K et al. all the malignant (C5) categories turned out to be malignant histologically. ${ }^{16}$

The tru-cut biopsy of palpable breast lesions based on a histological study of tissue specimens can provide all the reliable information. For small non- palpable lesions in breast lumps, tru-cut biopsy has replaced FNAC because sample insufficiency is rare for tru-cut biopsy even for these lesions. In this study, 19 cases had undergone both the FNA and CNB. The most common diagnosis in both the procedure was invasive carcinoma of no special type. A single case inadequate by FNAC was diagnosed in CNB. In a study performed by P. Garg et al. 29 cases were diagnosed as malignant on FNAC only 26 cases were diagnosed as malignant on CNB with 3 cases signed out as non-diagnostic for malignancy owing to non-sampling from the representative areas. ${ }^{17}$ Shashirekha et al. in their study concluded that in an experienced hand, the sensitivity of FNAC is high. Also, the inadequacy rate of FNAC for non-palpable lesions, the incidence of which has increased. However, it was almost similar in the current study. So, the overall performance indices of CNB are superior to FNAC in the majority of breast lesions. ${ }^{18}$

Studies carried out by Usami S et al, to compare CNB \& FNAC have reported very high sensitivity (91-99\%), specificity (96-100\%), positive predictive value (100\%) and negative predictive value (100\%) for CNB which are better than results for FNAC for both palpable and nonpalpable lesions. ${ }^{19}$ This concords with the findings of this study.

Compared to open surgery, tru-cut biopsy is much less invasive. For non-palpable lesions, surgery is omitted when the pathology is benign. It is a reliable method for histopathological diagnosis and offers the advantage over fine needle aspiration of providing enough material to perform IHC. However, there may be a concern that CNB may be less reliable than excisional biopsy due to the smaller sample size, sampling error on the heterogeneous tumor and/or crush artifacts in the CNB. This has major clinical implications since the expression of markers such as ER, PR and HER-2/neu will guide therapeutical planning. ${ }^{17}$ For malignant lesions, surgery can be done in a single setting.

A comparison of CNB with excisional biopsy findings revealed that $\mathrm{CNB}$ had $92.30 \%$ sample adequacy in diagnosing breast carcinoma. Sixty-nine patients with a breast CNB diagnosed as carcinoma followed by surgical excision of the tumor were assessed by Ricci et al. ${ }^{20}$ Similar to our study the histologic types determined in core biopsy correlated with the types determined in surgical biopsy (Table 3 ). In a study by Tamaki $\mathrm{K} \mathrm{et} \mathrm{al}{ }^{2}$ the cases that received four cores reached to $100 \%$ concordance in diagnosis between $\mathrm{CNB}$ and surgical specimens in contrast to our study. We had $85 \%$ concordance in correct histological subtyping. The 
reason may be due to presence of only one or two numbers of cores taken as we just started CNB in our institute.

Of the total 65 cases, $93.84 \%$ cases had undergone excisional biopsy and of these $87.69 \%$ cases of invasive carcinoma were graded according to the Elston-Ellis modification of Scarff-Bloom-Richardson grading system. WHO stated invasive carcinoma of no special type is the most common type of invasive carcinoma in breast comprising between $40 \%$ and $75 \%$ in different published series followed by invasive lobular carcinoma in $5-15 \%$ cases. ${ }^{21}$ In different studies, invasive carcinoma of no special type was seen in most $(92.8 \%)$ of the patients followed by invasive lobular carcinoma $(2.9 \%)$ and medullary carcinoma $(1.4 \%) .{ }^{22} \mathrm{~A}$ retrospective study of the clinico-pathological spectrum of carcinoma breast in a West Delhi, India by Nigam et al, showed that invasive carcinoma of no special type was the commonest variant comprising of $81.40 \%$ of cases followed by medullary carcinoma $10.36 \%$ and mucinous carcinoma $2.74 \% .{ }^{23}$ The distribution of histological types of breast carcinoma in the present study population was almost similar to that of other reported series.

In the present study, the most common histological grade was grade II (44.3\%) followed by grade I $(31.1 \%)$ and grade III $(24.6 \%)$ tumors. In comparison to our study, in a study performed by K. Geethamala et.al, the most common histologic grade encountered was grade II accounting to $54 \%$ followed by grades III and I with $27 \%$ and $19 \%$ respectively.24 The largest and most well-known study on histological grading by Elston and Ellis found 342 cases (19\%) of grade I, 631 cases (34\%) of grade II, and 857 cases (47\%) of grade III tumors. ${ }^{22}$

Estrogen receptor and progesterone receptor determinations are established procedures in the routine management of patients with breast cancer, primarily as predictive factors for response to therapeutic and adjuvant hormonal therapy. ${ }^{25}$ In the present study, there was a greater proportion of Triple negative breast carcinoma (35.6\%) compared to other studies. Of the total 16 triple negative cases, 13 cases were invasive carcinoma of no special type, a single case of carcinoma with medullary features, invasive lobular carcinoma and malignant phyllodes tumor respectively. In a study performed by Ali et al. one hundred and seventy of the investigated cases (65.9\%) were ER positive, PR positive and HER-2/neu negative. Simultaneous triple negative breast cancer occurred in $15.5 \%$ and simultaneous triple positive breast cancer occurred in $7.8 \%$ in contrary to our study. ${ }^{26}$

Hormonal receptor status has shown that the overall positivity rate for ER and PR was lower in India than that reported in Western literature. In the European and American population, $60-80 \%$ patients were found with positive receptor expression. ${ }^{27}$ This may be due to lower average age at diagnosis or racial difference. Triple negative cases were more common in Grade III (9/45) compared to grade II (4/45) and grade I (3/45). One of the reasons for triple negative grade I and II carcinomas in our study was due to the analysis of biomarkers in $\mathrm{CNB}$. $\mathrm{ER}+/ \mathrm{PR}+$ and HER-2/neu negative status were most common in grade I $(4 / 45)$ and grade II (7/45) carcinoma. The grade of tumors in the present study correlated to the expression of ER, PR as well as HER-2neu status. As shown by the other studies ${ }^{25}$, our results provide valuable prognostic information to guide the decision-making process for the treatment of the patient with invasive carcinoma.

\section{CONCLUSIONS}

Fine needle aspiration cytology of breast lesions is a safe, simple, minimally invasive, cost effective and sensitive method for cytological diagnosis. However, CNB was superior to FNAC in the diagnosis of breast lesions in terms of diagnostic accuracy and correct typing of benign and malignant cases. Thus, CNB is more specific and cost effective in giving a definitive histopathological diagnosis, therefore, avoiding unnecessary surgical management and can be used as an alternative to open biopsy. It also gives further information about tumor grade, lympho-vascular invasion, and receptor status. Biomarker status can be performed in a CNB specimen. The present study concludes that CNB permits the categorization of various types of breast malignancies which is helpful for the management of the patient. Thus, our results provide valuable prognostic and predictive information to guide the decision-making process for the treatment of a patient with invasive carcinoma.

\section{Conflict of interest: None}

\section{REFERENCES}

1. Moschetta M, Telegrafo M, Carluccio DA, et al. Comparison between fine needle aspiration cytology (FNAC) and core needle biopsy $(\mathrm{CNB})$ in the diagnosis of breast lesions. G Chir [Internet]. 2014;35(7-8):171-6. $\underline{\text { Crossref }}$

2. Tamaki KK, Sasano H, Ishida T, et al. Comparison of core needle biopsy (CNB) and surgical specimens for accurate preoperative evaluation of ER, PR and HER2 status of breast cancer patients. Cancer Science. 2010;101:2074-9. Crossref

3. Biswal P, Behera S, Kar A, et al. Correlation of Hormonal Receptors Estrogen Receptor, Progesterone Receptor and Her-2 / Neu with Tumor Characteristics in Breast Carcinoma: Study of 100 Consecutive Cases. Int J Clin Med. 2015;6:961-6. Crossref

4. Nakano S, Otsuka M, Mibu A, Oinuma T. Significance of fine needle aspiration cytology and vacuum-assisted core needle biopsy for small breast lesions. Clin Breast Cancer. 2015;15(1). Crossref

5. Zaha DC. Significance of immunohistochemistry in breast cancer. World J Clin Oncol. 2014;5(3). $\underline{\text { Crossref }}$

6. Thapa B, Singh Y, Sayami P, Shrestha U, Sapkota R, Sayami G. Breast cancer in young women from a low risk population in Nepal. Asian Pacific J Cancer Prev [Internet].2013;14(9):5095-9. Crossref

7. Pun CB, Pradhananga KK, Siwakoti B, Subedi K, Moore MA. Malignant neoplasm burden in Nepal - Data from the seven major cancer service hospitals for in Nepal. Asian Pacific J Cancer Prev. 2016;16(18):8659-63. Crossref 
8. Poudel KK, Huang Z, Neupane PR. Age specific incidence of five major cancers in Nepal, 2012. Nepal J Epidemiol [Internet]. 2016;6(2):565. Crossref

9. Ozsoy A, Barca N, Betul AD, Aktas H, Elverici E, Araz L, et al. The Relationship Between Breast Cancer and Risk Factors: A SingleCenter Study. Eur J Breast Heal[Internet].2017;13(3):145-9. Crossref

10. Ban KA, Godellas CV. Epidemiology of Breast Cancer. Surg Oncol Clin N Am. 2014;23(3):409-22. $\underline{\text { Crossref }}$

11. Rotunno M, Sun X, Figueroa J, Sherman ME, Garcia-Closas M, Meltzer P, et al. Parity-related molecular signatures and breast cancer subtypes by estrogen receptor status. Breast Cancer Res [Internet]. 2014;16(4). Crossref

12. Balekouzou A, Yin P, Pamatika CM, Bishwajit G, Nambei SW, Djeintote M, et al. Epidemiology of breast cancer: retrospective study in the Central African Republic. BMC Public Health. 2016;16(1). Crossref

13. Aljarrah A, Miller WR. Trends in the distribution of breast cancer over time in the southeast of Scotland and review of the literature. Ecancer Med Sci. 2014;8(1). Crossref

14. Deen S, Singh SJ, Kanojiya R, Chabra S, Dutt SC. A prospective study of breast lump and clinicopathological analysis in relation to malignancy: A review of 100 cases. IOSR J Dent Med Sci e-ISSN [Internet]. 2015 [cited 2018 Aug 31];14(11):127-32. Crossref

15. Rupom TU, Choudhury T, Banu SG. Study of Fine Needle Aspiration Cytology of Breast Lump: Correlation of Cytologically Malignant Cases with their Histological Findings. Bangabandhu Sheikh Mujib Med Univ J. 2011;4(2):2-6. DOI $\underline{\text { Crossref }}$

16. Mitra SK, Rajesh R, Mishra RK, Rai P, Vahikar S, Singhal P. Comparative evaluation of FNAC , core needle biopsy and excisional biopsy in subtyping of breast lesions. Trop J Pathol Microbiol. 2016;2(1):9 $\underline{\text { Crossref }}$

17. Garg P, Kaur H, Singh N, Puri A, Tayal I. Correlation of Fine needle aspiration cytology and Core Needle Biopsies in Breast carcinoma: Our experience. Ann Pathol Lab Med. 2016;3(6). 104. Crossref

18. Shashirekha CA, Singh R, Ravikiran HR, Sreeramulu PN, Prasad K. Fine needle aspiration cytology versus trucut biopsy in the diagnosis of breast cancer: A comparative study. Int Surg J. 2017;4(11):3718 21. DOI: $\underline{\text { Crossref }}$
19. Usami S, Moriya T, Kasajima A, Suzuki A, Ishida T, Sasano H, et al. Pathological aspects of core needle biopsy for non-palpable breast lesions. Breast Cancer [Internet].2005;12(4):272-8. Crossref

20. Ricci M, Calvano F, Cabral C, et al. Analysis of the concordance rates between core needle biopsy and surgical excision in patients with breast cancer. Rev Assoc Med Bras [Internet]. 2012;58(5):532-536. Crossref

21. Lakhani SR, Ellis IO, Shnitt SJ, Tan PH, Vijver MJ. (ed.) WHO Classification of Tumours of the Breast. 4th ed. Lyon, IARC; 2012. Crossref

22. Saha K, Raychaudhuri G, Chattopadhyay B. Clinico-pathological study of breast carcinoma: A prospective two-year study in a tertiary care hospital. Clin Cancer Investig J. 2013;2(1):34. Crossref

23. Nigam J, Sood N, Yadav P. A retrospective study of clinicopathological spectrum of carcinoma breast in a West Delhi, India. South Asian J Cancer [Internet]. 2014;3(3):179. $\underline{\text { Crossref }}$

24. Geethamala K, Murthy VS, Vani B, Sudharao. Hormone receptor expression in breast carcinoma at our hospital. Clin Cancer Investig J. 2015;4(4):511-5. Crossref

25. Fitzgibbons P, Page D, Weaver D, Thor A, Allred D, Clark G, et al. Prognostic Factors in Breast Cancer. Arch Pathol Lab Med. 2000;124(7):966-78. 105. Crossref

26. Ali EM, Ahmed ARH, Ali AMA. Correlation of Breast Cancer Subtypes Based on ER, PR and HER2 Expression with Axillary Lymph Node Status. Cancer Oncol Res [Internet]. 2014;2(4):51-7. $\underline{\text { Crossref }}$

27. Mittal A, Prasad C, Sreeramulu P, Srinivasan D, Joshi R. Histopathological Grade versus Estrogen and Progestron Receptor Status in Carcinoma Breast- A Single Center Study. Open Access J Surg. 2017;4(3):10-3. $\underline{\text { Crossref }}$ 